\title{
PENGARUH TEKANAN GAS PADA PENGELASAN OXI ASETILEN WELDING TERHADAP KEKUATAN TARIK DAN KETANGGUHAN PADA BAHAN ALUMUNIUM-MAGNESIUM
}

\author{
Yudi Pratama ${ }^{1}$, M. Sabri ${ }^{2}$, Ikhwansyah Isranuri ${ }^{3}$, Marragi M. ${ }^{4}$, Darwin Sitormpul $^{5}$ \\ 1,2,3,4,5 Departemen Teknik Mesin, Fakultas Teknik Universitas Sumatera Utara \\ Email: Yudie049@yahoo.com
}

\begin{abstract}
ABSTRAK
Pembangunan konstruksi dengan menggunakan logam pada masa sekarang ini banyak melibatkan unsur pengelasan khususnya bidang rancang bangun karena sambungan las merupakan salah satu pembuatan sambungan yang secara teknis memerlukan keterampilan yang tinggi bagi pengelas agar diperoleh sambungan dengan kualitas baik. Tujuan dari penelitian ini adalah untuk mendapatkan nilai ketangguhan sambungan las pada material aluminium magnesium serta karakterisitik hasil pengelasan dengan variasi tekanan gas oxy asetilen . pada penelitian ini menggunakan campuran logam aluminium-magnesium pada pengelasan oxy asetilen welding (OAW) dengan variasi tekanan $\mathrm{O} 2 \mathrm{llb}, \mathrm{c} 2 \mathrm{~h} 2 \mathrm{3lb} / \mathrm{m}^{2}$ dan tekanan $\mathrm{O} 22$ $\mathrm{lb}, \mathrm{c} 2 \mathrm{~h} 2 \mathrm{blb} / \mathrm{m}^{2}$. Hasil pengujian pada penelitian ini meliputi hasil pengujian Tarik, di mana pada tekanan $\mathrm{O} 21 \mathrm{lb}, \mathrm{c} 2 \mathrm{~h} 2$ 3lb/m memiliki nilai tegangan rata-rata 85,6 MPa dan nilai regangan rata-rata 2,38 \%, pada tekanan $\mathrm{O} 22 \mathrm{lb}, \mathrm{c} 2 \mathrm{~h} 26 \mathrm{lb} / \mathrm{m}^{2}$ nilai tegangan rata-rata $112 \mathrm{MPa}$ dan nilai regangan rata-rata $1,88 \%$.pada pengujian Impact nilai rata-rata energi yang di serap pada tekanan $\mathrm{O} 21 \mathrm{lb}, \mathrm{c} 2 \mathrm{~h} 23 \mathrm{lb} / \mathrm{m}^{2} 23,85 \mathrm{~J}$ dan pada tekanan $\mathrm{O} 22 \mathrm{lb}, \mathrm{c} 2 \mathrm{~h} 26 \mathrm{lb} / \mathrm{m}^{2} 23,17 \mathrm{~J}$, pengujian kekerasan pada tekanan $\mathrm{O} 21 \mathrm{lb}, \mathrm{c} 2 \mathrm{~h} 2 \mathrm{llb} / \mathrm{m}^{2}$ nilai BHN rata-rata 97,53 dan pada tekanan $\mathrm{O} 22 \mathrm{lb}, \mathrm{c} 2 \mathrm{~h} 26 \mathrm{lb} / \mathrm{m}^{2}$ nilai BHN rata-rata 81,63,dan Metallografi.dimana pada pengujian metalografi terlihat warna putih keperakan menunjukan aluminium dan butiran berwarna hitam menunjukan magnesium. Di mana pada tekanan $\mathrm{O} 21 \mathrm{lb}, \mathrm{c} 2 \mathrm{~h} 2 \mathrm{2lb} / \mathrm{m}^{2}$ terdapat lubang-lubang kecil ( porositas ),sementara pada tekanan $\mathrm{O} 22 \mathrm{lb}, \mathrm{c} 2 \mathrm{~h} 2 \mathrm{6lb} / \mathrm{m}$ hampir tidak memiliki lubang-lubang kecil ( porositas ).
\end{abstract}

Kata kunci : Aluminium-Magnesium, Oxy Asetilen,pengujian tarik, impact, kekerasan, metallografi

\section{ABSTRACT}

Using metal construction at the present time involvees many elements, particularly the field of welding engineering for welded joints is one of making connections that technically requires high skills for welding in order to obtain a connection with good quality. The purpose of this study is to obtain the value of the material toughness of welded joints in aluminum and magnesium welding characteristics results with oxy acetylene gas pressure variation . in this study using aluminum - magnesium alloys in welding oxy acetylene welding ( $\ddot{O A W}$ ) with pressure variations $\mathrm{O} 21 \mathrm{lb}, \mathrm{C} 2 \mathrm{H} 23 \mathrm{LB} / \mathrm{m}^{2}$ and a pressure of $2 \mathrm{lb} \mathrm{O2}, \mathrm{C} 2 \mathrm{H} 2 \mathrm{6lb} / \mathrm{m}^{2}$. The test results on the study include Pull test results, where the pressure of 1 lb $\mathrm{O} 2, \mathrm{C2H} 23 \mathrm{LB} / \mathrm{m}^{2}$ has an average voltage value $85.6 \mathrm{MPa}$ and an average strain value of $2.38 \%$, at a pressure of $2 \mathrm{lb} \mathrm{O2}, \mathrm{C} 2 \mathrm{H} 26 \mathrm{lb} / \mathrm{m}^{2}$ average voltage value of $112 \mathrm{MPa}$ and an average strain value of $1.88 \%$.In Impact testing of the average value of energy absorbed at a pressure of $1 \mathrm{lb} \mathrm{O2}, \mathrm{C} 2 \mathrm{H} 2 \mathrm{LLB} /$ $m^{2} 23,85 \mathrm{~J}$ and at a pressure $\mathrm{O} 22 \mathrm{lb}, 6 \mathrm{lb} C 2 \mathrm{H2} / \mathrm{m}^{2} 23.17 \mathrm{~J}$, hardness testing at a pressure of $1 \mathrm{lb} \mathrm{O} 2$,

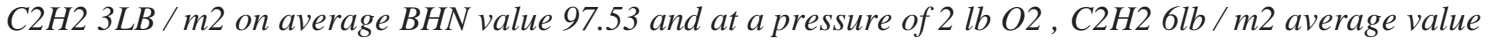
BHN 81.63 and Metallografi. where the metallographic examination showed visible white silvery aluminum and magnesium showed black granules. Where the pressure of $1 \mathrm{lb} \mathrm{O2}, \mathrm{C} 2 \mathrm{H} 2 \mathrm{llb} / \mathrm{m}^{2}$ there are small holes ( porosity), while the pressure of $2 \mathrm{lb} \mathrm{O2}, \mathrm{C} 2 \mathrm{H} 2 \mathrm{6lb} / \mathrm{m}^{2}$ hardly have small holes ( porosity).

Keywords : Aluminium - Magnesium, Oxy Acetylene, tensile testing, impact, hardness, metallografi

\section{PENDAHULUAN}

Pengelasan dengan oxy-acetylene adalah proses pengelasan secara manual dengan pemanasan permukaan logam yang akan dilas atau disambung sampai mencair 
oleh nyala gas acetylene melalui pembakaran $\mathrm{C}_{2} \mathrm{H}_{2}$ dengan gas $\mathrm{O}_{2}$ dengan atau tanpa logam pengisi. Proses penyambungan dapat dilakukan dengan tekanan sangat tinggi sehingga dapat mencairkan logam.

Pengelasan dengan gas dilakukan dengan membakar bahan bakar gas yang dicampur dengan oksigen $\left(\mathrm{O}_{2}\right)$ sehingga menimbulkan nyala api dengan suhu tinggi $\left(3000^{\circ} \mathrm{C}\right)$ yang mampu mencairkan logam induk dan logam pengisinya. Jenis bahan bakar gas yang digunakan adalah acetylene, propana atau hidrogen, sehingga cara pengelasan ini dinamakan las oxy-acetylene atau dikenal dengan nama las karbit.

Nyala asetilen diperoleh dari nyala gas campuran oksigen dan asetilen yang digunakan untuk memanaskan logam sampai mencapai titik cair logam induk. Pengelasan dapat dilakukan dengan atau tanpa logam pengisi.Oksigen diperoleh dari proses elektrolisa atau proses pencairan udara. Oksigen komersil umumnya berasal dari proses pencairan udara dimana oksigen dipisahkan dari nitrogen. Oksigen ini disimpan dalam silinder baja pada tekanan $14 \mathrm{MPa}$.Gas asetilen $\left(\mathrm{C}_{2} \mathrm{H}_{2}\right)$ dihasilkan dari reaksi kalsium karbida dengan air.Gelembung-gelembung gas naik dan endapan yang terjadi adalah kapur tohor. Reaksi yang terjadi dalam tabung asetilen adalah:

$$
\underset{2 .}{\longrightarrow} 2 \mathrm{C}_{2} \mathrm{H}_{2}+5 \mathrm{O}_{2} \quad 4 \mathrm{CO}_{2}+\mathrm{H}_{2} \mathrm{O}
$$

Kekuatan hasil lasan dipengaruhi oleh tekanan gas oxy asetilen dan kecepatan pengelasan. Penentuan besarnya tekanan gas dalam penyambungan logam menggunakan OAW mempengaruhi efisiensi pekerjaan dan bahann las.

\section{TINJAUAN PUSTAKA}

a.Paduan Aluminium

Paduan aluminium merupakan material utama yang saat ini digunakan dibanyak industri. Aluminium dipilih karena memiliki sifat ringan dan kekuatannya dapat dibentuk dengan cara dipadu dengan unsur lain. Permasalahan yang dihadapi adalah pemilihan jenis unsur apa yang akan dipadu dengan aluminium untuk mendapatkan karakteristik material yang dibutuhkan. Paduan logam ringan yang mempunyai kekuatan tinggi terhadap korosi [1].

Pengelasan (welding) adalah salah salah satu teknik penyambungan logam dengan cara mencairkan sebagian logam induk dan logam pengisi dengan atau tanpa tekanan dan dengan atau tanpa logam penambah dan menghasilkan sambungan yang continue.

Definisi pengelasan menurut DIN (Deutsche Industrie Normen) adalah ikatan metalurgi pada sambungan logam atau logam paduan yang dilaksanakan dalam keadaan lumer atau cair. Dengan kata lain, las adalah sambungan setempat dari beberapa batang logam dengan menggunakan energi panas. Dalam proses penyambungan ini adakalanya disertai dengan tekanan dan material tambahan (filler material)[2].

b.Las Oxy-acetylene

Ada tiga jenis nyala api dalam las oxy-asetilen yaitu:

1.Nyala asetilen lebih (Nyala karburasi)

2.Nyala oksigen lebih (Nyala oksidasi)

3.Nyala netral

c. Cacat Pada Las

cacat las dibagi atas tiga kelompok yakni [3] :

1. Kelompok cacat visual

2. Kelompok cacat non visual

3. Kelompok cacat internal 


\section{d. Uji Impak}

Batang uji metode charpy memiliki spesifikasi, luas penampang $10 \mathrm{~mm}$ x $10 \mathrm{~mm}$, takik berbentuk V. Proses pembebanan uji impak pada metode ini dengan sudut $45^{\circ}$, kedalaman takik $2 \mathrm{~mm}$ dengan radius pusat $0.25 \mathrm{~mm}$.

Spesimen kemudian diletakkan horizontal pada batang penumpu dan diberi beban secara tiba-tiba di belakang sisi takik oleh pendulum berat berayun (kecepatan pembebanan $\pm 5 \mathrm{~m} / \mathrm{s}$ ). [4].

Pada baja dan aluminium terdapat perbedaan harga impak.Harga impak baja lebih tinggi daripada aluminium. Ketangguhan adalah kemampuan material untuk menyerap energi dan berdeformasi plastis hingga patah.

Jenis perpatahan yang terjadi.

1. Patahan Getas

2. Patahan Liat

3. Patahan Campuran

\section{e.Uji Tarik}

Proses pengujian tarik bertujuan untuk mengetahui kekuatan tarik benda uji. Pengujian tarik untuk kekuatan tarik daerah las dimaksudkan untuk mengetahui apakah kekuatan las mempunyai nilai yang sama, lebih rendah atau lebih tinggi dari kelompok raw materials. Pengujian tarik untuk kualitas kekuatan tarik dimaksudkan untuk mengetahui berapa nilai kekuatannya dan dimanakah letak putusnya suatu sambungan las. Pembebanan tarik adalah pembebanan yang diberikan pada benda dengan memberikan gaya tarik berlawanan arah pada salah satu ujung benda. Proses terjadinya deformasi pada bahan uji adalah proses pergeseran butiran kristal logam yang mengakibatkan melemahnya gaya elektromagnetik setiap atom logam hingga terlepas ikatan tersebut oleh penarikan gaya maksimum.Pada pengujian tarik beban diberikan secara kontinu dan pelan-pelan bertambah besar, bersamaan dengan itu dilakukan pengamatan mengenai perpanjangan yang dialami benda uji dan dihasilkan kurva tegangan regangan.

\section{f. Uji Kekerasan (Hardness Test)}

Proses pengujian kekerasan logam dapat diartikan sebagai kemampuan suatu bahan terhadap pembebanan dalam perubahan yang tetap.Harga kekerasan bahan tersebut dapat dianalisis dari besarnya pembebanan yang diberikan terhadap luasan bidang yang menerima pembebanan.Pengujian kekerasan logam ini secara garis besar ada 3 jenis yaitu cara goresan, penekanan, cara dinamik. Proses pengujian yang mudah dan cepat dalam memperoleh angka kekerasan yaitu penekanan. Penentuan kekerasan penekanan ada 3 cara yaitu Brinell, Vickers, dan Rockwell. Pada penelitian ini digunakan cara mikro Vickers dengan menggunakan penekan berbentuk piramida intan. Besar sudut antara permukaan piramida yang saling berhadapan 1360

\section{g. Photo Mikro (Metalografi)}

Analisa mikro adalah suatu analisa mengenai struktur logam melalui pembesaran dengan menggunakan mikroskop khusus metalografi. Dengan analisa mikro struktur, kita dapat mengamati bentuk dan ukuran kristal logam, kerusakan logam akibat proses deformasi, proses perlakuan panas, dan perbedaan komposisi.Sifat-sifat logam terutama sifat mekanis dan sifat teknologis sangat mempengaruhi oleh mikro struktur logam dan paduannya. Struktur mikro dari logam dapat diubah dengan jalan perlakuan panas ataupun dengan proses perubahan bentuk (deformasi) dari logam yang 
akan diuji. Pengamatan metalografi dengan mikroskop optik dapat dibagi dua, yaitu: metalografi makro yaitu pengamatan struktur dengan perbesaran 10 - 100 kali dan metalografi mikro yaitu pengamatan struktur dengan perbesaran diatas 100 kali.

\section{METODE PENELITIAN Waktu dan Tempat}

Penelitian ini dilakukan di Laboratorium Ilmu Logam Fisik Departemen Teknik Mesin Fakultas Teknik Universitas Sumatera Utara. Penelitian ini dilaksanakan mulai bulan Juli sampai dengan bulan Agustus.

\section{Bahan}

Bahan yang dipergunakan dalam penelitian ini adalah Aluminium-magnesium dalam bentuk specimen. karena Aluminium-Magnesium banyak digunakan di industri seperti pembuatan kapal.pada proses pengelasan Aluminium-magnesium memerlukan keterampilan khusus dalam proses lasan.dan proses pembuatan Spesimen dilakukan dengan pengecoran tradisional.

\section{Pembuatan spesimen}

Spesimen uji tarik

Setelah pengelasan selesai maka dilanjutkan pembuatan specimen yang nantinya akan di uji tarik,Bahan dipotong-potong dengan ukuran panjang $200 \mathrm{~mm}$ dan lebar 22 mm.seperti di tunjukan pada gambar 1 berikut:

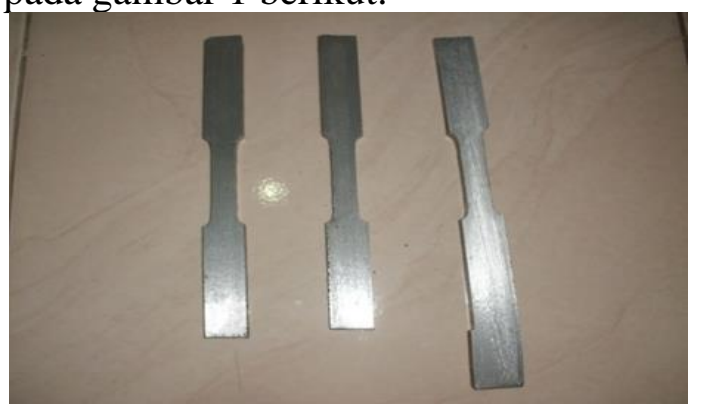

Gambar 1 bentuk spesimen uji tarik

Spesimen Uji Impak

Setelah pengelasan selesai maka dilanjutkan pembuatan specimen yang nantinya akan di uji impak.seperti dI tujunkan pada gambar 2 berikut:

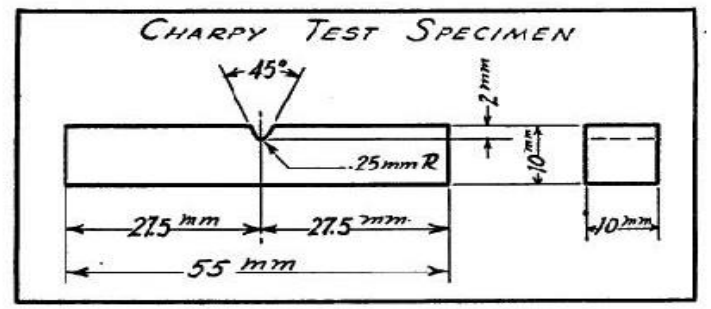

Gambar 2 bentuk dan ukuran spesimen uji impact.

Specimen Uji Kekerasan

Setelah pengelasan selesai maka dilanjutkan pembuatan specimen yang nantinya akan di uji tarik,Bahan dipotong-potong dengan ukuran panjang $200 \mathrm{~mm}$ dan lebar 18 $\mathrm{mm}$. 


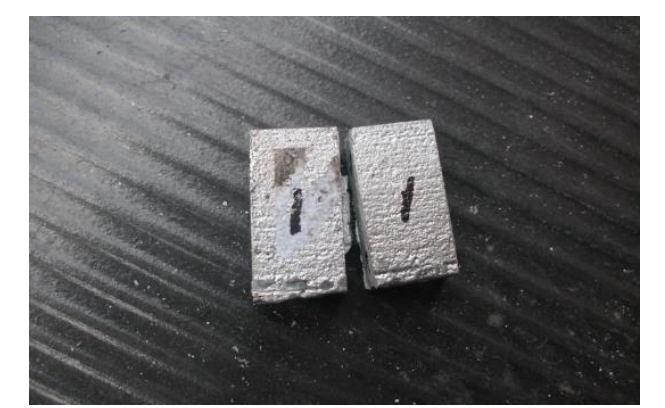

Gambar 3 bentuk spsesimen uji kekerasan

\section{Proses Pengujian}

Uji Impak

Prosedur dan pembacaan hasil pada pengujian ketangguhan adalah sebagai berikut:

1. Menyiapkan peralatan mesin impact Charpy.

2. Menyiapkan benda uji yang akan dilakukan pengujian sesuai standar ukuran yang telah ditetapkan.

3. Meletakkan benda uji pada anvil dengan posisi takikan membelakangi arah ayunan palu Charpy.

4. Menaikkan palu Charpy pada kedudukan $147^{\circ}$ (sudut $\alpha$ ) dengan menggunakan handle pengatur kemudian dikunci.

5. Putar jarum penunjuk sampai berimpit pada kedudukan $147^{\circ}$.

6. Lepaskan kunci sehingga palu Charpy berayun membentur benda uji.

Memperhatikan dengan mencatat sudut $\beta$ dan nilai tenaga patah.

Uji Tarik (Tensile)

Prosedur dan pembacaan hasil pada pengujian tarik adalah sebagai berikut. Benda uji dijepit pada ragum uji tarik, setelah sebelumnya diketahui penampangnya, panjang awalnya dan ketebalannya.Langkah pengujian sebagai berikut :

1. Menyiapkan kertas milimeter block dan letakkan kertas tersebut pada plotter.

2. Benda uji mulai mendapat beban tarik dengan menggunakan tenaga hidrolik diawali $0 \mathrm{~kg}$ hingga benda putus pada beban maksimum yang dapat ditahan benda tersebut.

3. Benda uji yang sudah putus lalu diukur berapa besar penampang dan panjang benda uji setelah putus.

4, Gaya atau beban yang maksimum ditandai dengan putusnya benda uji terdapat pada layar digital dan dicatat sebagai data.

5. Hasil diagram terdapat pada kertas milimeter block yang ada pada meja plotter.

6. Hal terakhir yaitu menghitung kekuatan tarik, kekuatan luluh,perpanjangan, reduksi penampang dari data yang telah didapat dengan menggunakan persamaan yang ada.

\section{Uji Kekerasan(Hardness)}

Spesimen yang telah di foto mikro, selanjutnya digunakan untuk pengujian kekerasan.Spesimen sebelumnya dipoles terlebih dahulu dengan menggunakan autosol, kemudian dietsa jenis HNO3.Langkah pengujian :

1. Memasang indentor piramida intan. Penekanan piramida intan 1360 dipasang pada tempat indentor mesin uji, kencangkan secukupnya agar penekan intan tidak jatuh.

2. Memberi garis warna pada daerah logam las, HAZ dan logam induk yang akan diuji.

3. Meletakkan benda uji di atas landasan.

4. Menentukan beban utama sebesar $1 \mathrm{kgf}$.

5. Menentukan titik yang akan diuji. 


\section{Menekan tombol indentor.}

Foto Struktur Mikro

Sebelum melakukan pengujian foto struktur mikro benda uji perlu di poles dahulu. Pemolesan dengan menggunakan ampelas grade 80 sampai 1500, kemudian diberi autosol agar spesimen lebih halus lagi.Spesimen yang telah diproses dilanjutkan dengan pengujian foto struktur mikro, adapun langkah-langkahnya sebagai berikut:

1. Spesimen dibersihkan menggunakan kain, karena spesimen lebih besar dari tempat etsa maka pengetsaan menggunakan kapas yang dibasahi cairan etsa kemudian dioleskan pada permukaan yang dikehendaki.Setelah selesai dioles dengan cairan etsa kemudian dibilas dengan alkohol.

2. Letakkan spesimen pada landasan mikroskop optik, aktifkan mesin,dekatkan lensa pembesar untuk melihat permukaan spesimen.Pengambilan foto struktur mikro dengan perbesaran 200x dan 500x.Lihatlah struktur mikro apabila kurang jelas atau kabur, fokuskan lensa agar terlihat dengan jelas.

3. Sebelum gambar diambil, film dipasang pada kamera yang telah disetel sedemikian rupa dengan menggunakan film asa 200 . Usahakan pada saat pengambilan foto tidak ada hal apapun yang membuat mikroskop optik bergerak.

karena apabila mikroskop optik bergerak.

\section{HASIL DAN ANALISA}

Hasil pengujian Impak

Pengujian dilakukan dengan menggunakan metode Charpy dengan sudut awal pemukulan $147^{\circ}$. Dibawah ini hasil pengujian impak yang dilakukan di laboratorium FT.USU jurusan Teknik Mesin di laboratorium Ilmu Logam.

Pengujian dilakukan untuk mengetahui ketangguhan pada bahan Aluminiummagnesium dengan variasi tekanan $\mathrm{O} 2 \mathrm{llb}, \mathrm{c} 2 \mathrm{~h} 2 \mathrm{llb} / \mathrm{m}^{2}$ dan $\mathrm{O} 22 \mathrm{lb}, \mathrm{c} 2 \mathrm{~h} 2 \mathrm{6lb} / \mathrm{m}^{2}$.

Energi yang diserap (E) dari masing-masing spesimen pada tekanan $\mathrm{O} 2 \mathrm{llb}, \mathrm{c} 2 \mathrm{~h} 2$ $3 \mathrm{lb} / \mathrm{m}^{2}$ adalah :

Spesimen I : 23,51 J

Spesimen II : 24,54 J

Spesimen III : 23,51 J

Energi yang diserap (E) dari masing-masing spesimen pada tekanan $\mathrm{O} 22 \mathrm{lb}, \mathrm{c} 2 \mathrm{~h} 2$ $6 \mathrm{lb} / \mathrm{m}^{2}$ adalah :

Spesimen I : 23,51 J

Spesimen II : 23,51 J

Spesimen III : 22,49 J

Hasil Pengujian Tarik

1. Spesimen I

Berikut hasil pengujian tarik dengan tekanan $\mathrm{O} 2 \mathrm{llb}, \mathrm{c} 2 \mathrm{~h} 2 \mathrm{3lb} / \mathrm{m}^{2}$

Dari kurva pengujian tarik spesimen I dengan tekanan O2 1lb,c2h2 3lb/m² terlihat beban maks $1150 \mathrm{kgf}$, beban patah $1000 \mathrm{kgf}$ dan beban yield $850 \mathrm{kgf}$.

Kurva hasil pengujian tarik spesimen I dengan tekanan $\mathrm{O} 2 \mathrm{llb}, \mathrm{c} 2 \mathrm{~h} 23 \mathrm{lb} / \mathrm{m}^{2}$ dapat dilihat pada gambar 4 berikut. 


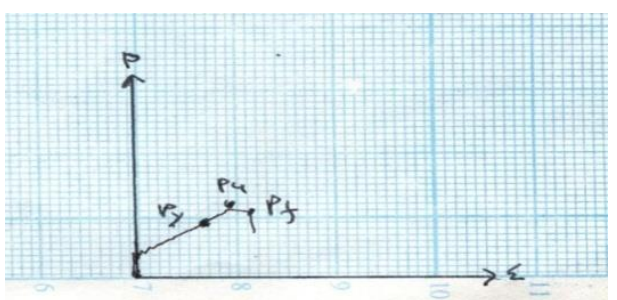

Gambar 4 kurva hasil uji tarik P ( kgf) vs \& (elongation) spesimen I.

Nilai tegangan pada spesimen I adalah $76 \mathrm{MPa}$ dan nilai regangan 3,82 \%.

\section{Spesimen II}

Dari kurva pengujian tarik spesimen I dengan tekanan $\mathrm{O} 2 \mathrm{llb}, \mathrm{c} 2 \mathrm{~h} 2 \mathrm{llb} / \mathrm{m}^{2}$ terlihat beban maks $1400 \mathrm{kgf}$, beban patah $1200 \mathrm{kgf}$ dan beban yield $1050 \mathrm{kgf}$.

Kurva hasil pengujian tarik spesimen I dengan tekanan $\mathrm{O} 2 \mathrm{llb}, \mathrm{c} 2 \mathrm{~h} 2 \mathrm{3lb} / \mathrm{m}^{2}$ dapat dilihat pada gambar 5 berikut.

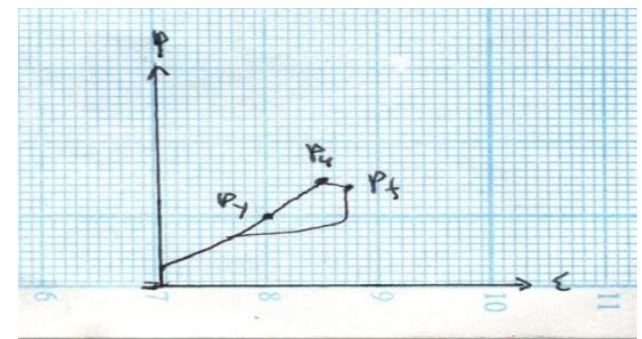

Gambar 5 kurva hasil uji tarik P ( kgf) vs $\varepsilon$ (elongation) spesimen II

Nilai tegangan pada spesimen II adalah $95 \mathrm{MPa}$ dan nilai regangan 2,23\%.

\section{Spesimen III}

Dari kurva pengujian tarik spesimen I dengan tekanan $\mathrm{O} 2 \mathrm{llb}, \mathrm{c} 2 \mathrm{~h} 2 \mathrm{lb} / \mathrm{m}^{2}$ terlihat beban maks $1450 \mathrm{kgf}$, beban patah $1250 \mathrm{kgf}$ dan beban yield $1000 \mathrm{kgf}$.

Kurva hasil pengujian tarik spesimen I dengan tekanan O2 1lb,c2h2 3lb/m² dapat dilihat pada gambar 6 berikut.

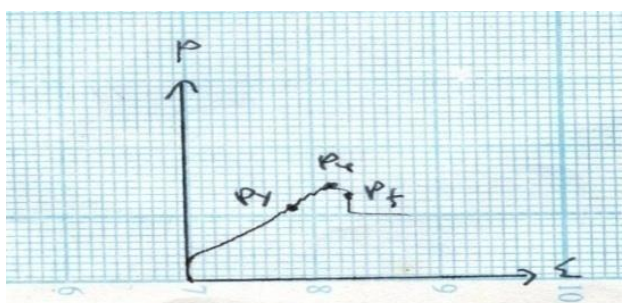

Gambar 6 kurva hasil uji tarik P ( kgf) vs \& (elongation) spesimen III.

Nilai tegangan pada spesimen III adalah $86 \mathrm{MPa}$ dan nilai regangan 1,10\%.

Berikut hasil pengujian tarik dengan tekanan $\mathrm{O} 22 \mathrm{lb}, \mathrm{c} 2 \mathrm{~h} 2 \mathrm{blb} / \mathrm{m}^{2}$

\section{Spesimen I}

Dari kurva pengujian tarik spesimen I dengan tekanan O2 $2 \mathrm{lb}, \mathrm{c} 2 \mathrm{~h} 2 \mathrm{llb} / \mathrm{m}^{2}$ terlihat beban maks $1400 \mathrm{kgf}$, beban patah $1250 \mathrm{kgf}$ dan beban yield $1100 \mathrm{kgf}$. 
Kurva hasil pengujian tarik spesimen I dengan tekanan $\mathrm{O} 22 \mathrm{lb}, \mathrm{c} 2 \mathrm{~h} 2 \mathrm{lb} / \mathrm{m}^{2}$ dapat dilihat pada gambar 7 berikut.

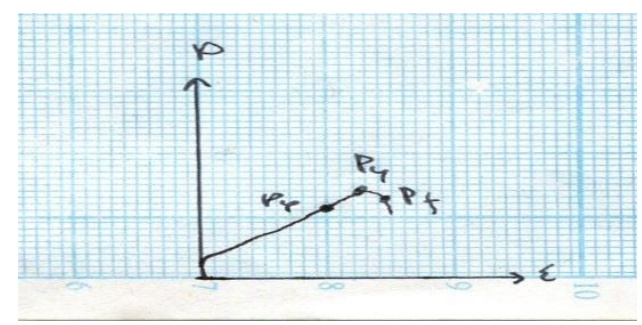

Gambar 7 kurva hasil uji tarik P ( kgf) vs $\varepsilon$ (elongation) spesimen I. Nilai tegangan pada spesimen I adalah $105 \mathrm{MPa}$ dan nilai regangan 1,96\%.

\section{Spesimen II}

Dari kurva pengujian tarik spesimen I dengan tekanan O2 $2 \mathrm{lb}, \mathrm{c} 2 \mathrm{~h} 2 \mathrm{llb} / \mathrm{m}^{2}$ terlihat beban maks $1600 \mathrm{kgf}$, beban patah $1500 \mathrm{kgf}$ dan beban yield $1250 \mathrm{kgf}$.

Kurva hasil pengujian tarik spesimen I dengan tekanan O2 $2 \mathrm{lb}, \mathrm{c} 2 \mathrm{~h} 2 \mathrm{6lb} / \mathrm{m}^{2}$ dapat dilihat pada gambar 8 berikut.

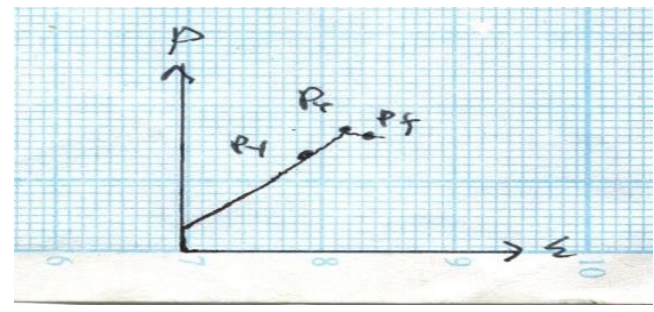

Gambar 8 kurva hasil uji tarik P ( kgf) vs $\varepsilon$ (elongation) spesimen II. Nilai tegangan pada spesimen II adalah $113 \mathrm{MPa}$ dan nilai regangan 2,48 \%.

\section{Spesimen III}

Dari kurva pengujian tarik spesimen I dengan tekanan $\mathrm{O} 22 \mathrm{lb}, \mathrm{c} 2 \mathrm{~h} 2 \mathrm{lb} / \mathrm{m}^{2}$ terlihat beban maks $1750 \mathrm{kgf}$, beban patah $1650 \mathrm{kgf}$ dan beban yield $1200 \mathrm{kgf}$.

Kurva hasil pengujian tarik spesimen I dengan tekanan $\mathrm{O} 22 \mathrm{lb}, \mathrm{c} 2 \mathrm{~h} 2 \mathrm{6lb} / \mathrm{m}^{2}$ dapat dilihat pada gambar 9 berikut.

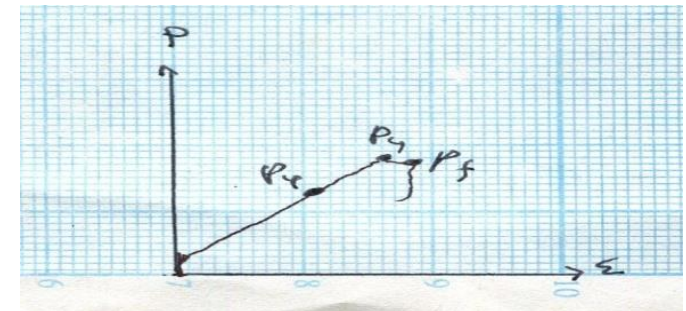

Gambar 9 kurva hasil uji tarik P ( kgf) vs $\varepsilon$ (elongation)spesimen III. Nilai tegangan pada spesimen III adalah $118 \mathrm{MPa}$ dan nilai regangan 1,20\%. 
Gambar 10 grafik Tegangan vs Regangan pada tekanan O2 1lb,c2h2 3lb/m²

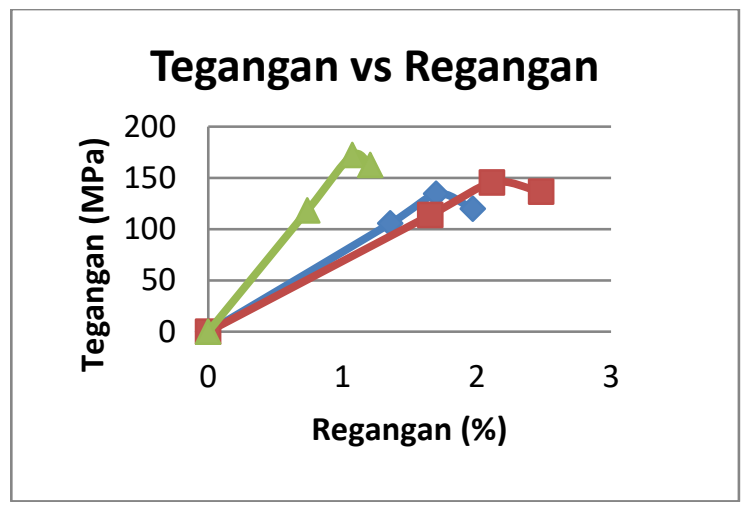

Gambar 11 grafik Tegangan vs Regangan pada tekanan O2 2 lb,c2h2 6lb/m².

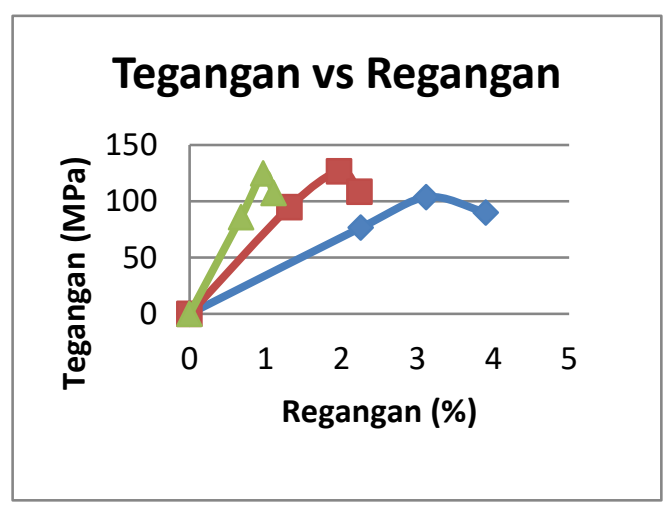

\section{Hasil Uji Kekerasan}

Kekerasan merupakan ukuran ketahanan bahan terhadap deformasi tekan. Sebuah indentor yang keras ditekankan kepermukaan logam yang diuji. Depormasi yang terjadi merupakan kombinasi prilaku elastis dan plastis, akan tetapi kekerasan umumnya hanya berkaitan dengan sifat plastis dan hanya untuk sebagian kecil bergantung pada sifat elastis. Pengujian kekerasan dalam penelitian ini dilakukan agar dapat diketahui pengaruh lasan dengan variasi tekanan $\quad \mathrm{O} 21 \mathrm{lb}, \mathrm{c} 2 \mathrm{~h} 2 \mathrm{3lb} / \mathrm{m}^{2}$ dan $\mathrm{O} 22$ $\mathrm{lb}, \mathrm{c} 2 \mathrm{~h} 26 \mathrm{lb} / \mathrm{m}^{2}$.

Penghitungan nilai kekerasan dari benda uji yang dilakukan dalam penelitian ini adalah dengan menggunakan skala Brinell yang bekas injakannya atau indentasinya dapat dilihat dengan teropong Indentor dan nilai BHN-nya disesuaikan dengan tabel kekerasan.

Hasil dari pengujian Brinell pada tekanan $\mathrm{O} 2 \mathrm{1lb}, \mathrm{c} 2 \mathrm{~h} 2 \mathrm{lb} / \mathrm{m}^{2}$ dari masingmasing spesimen adalah:

Spesimen I : 100

Spesimen II : 92,6

Spesimen III : 100

Hasil dari pengujian Brinell pada tekanan O2 $2 \mathrm{lb}, \mathrm{c} 2 \mathrm{~h} 2 \mathrm{blb} / \mathrm{m}^{2}$ dari masingmasing spesimen adalah:

Spesimen I : 85,7

Spesimen II : 79,6

Spesimen III : 79,6 


\section{Hasil Pengujian Metalografi (Stuktur Mikro)}

Tujuan dari pengujian ini adalah untuk mngetahui struktur mikro pada material yang mengalami perlakuan panas pada daerah sekitar pengelasan tungsten inert gas. Untk mengetahui struktur mikro dari suatu logam pada umumnya pengujian dilakukan dengan reflek pemendaran ( sinar ),pada pemolesan atau etsa, tergantung pada permukaan logam uji polis, dan diperiksa dibawah mikroskop.

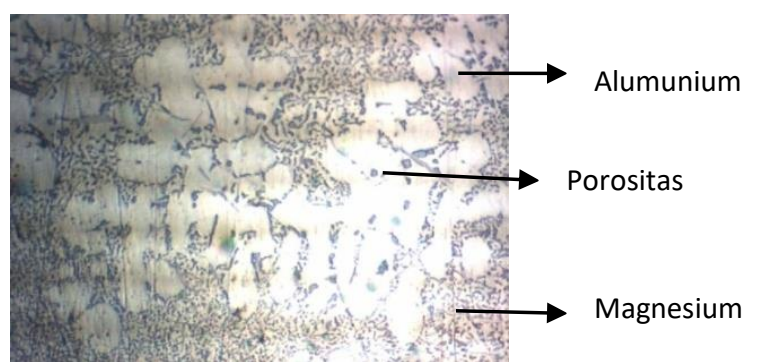

Gambar 4.16 Struktur mikro Al-Mg pada pembesaran 200X dengan tekanan O2 $1 \mathrm{lb}, \mathrm{c} 2 \mathrm{~h} 2 \mathrm{llb} / \mathrm{m}^{2}$

Pada gambar diatas menunjukan hasil uji metalografi pada tekanan $\mathrm{O} 2 \mathrm{llb}, \mathrm{c} 2 \mathrm{~h} 2$ $3 \mathrm{lb} / \mathrm{m}^{2}$, terlihat banyaknya lubang-lubang atau ruang-ruang kosong diantara material ( porositas ), hal ini disebut juga dengan salah satu cacat pengelasan yang disebabkan karena terkontaminasinya logam las dalam bentuk gas yang terperangkap,sehingga didalam logam las terdapat rongga-rongga.Porositas terjadi karena pada pengelasan dengan tekanan $\mathrm{O} 2 \mathrm{llb}, \mathrm{c} 2 \mathrm{~h} 2 \mathrm{3lb} / \mathrm{m}^{2}$ mengalami proses pemanasan yang lama,sehingga pada saat pendinginan juga lama,sehingga terjadi gumpalan gas yang terperangkap.

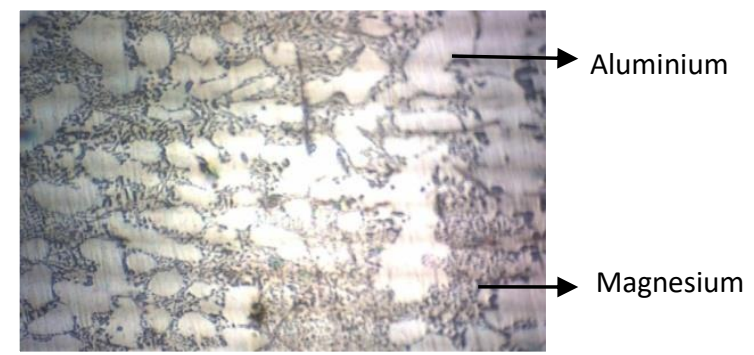

Gambar 4.14 Struktur mikro Al-Mg pada pembesaran $200 X$ Dengan tekanan O2 $3 \mathrm{lb}, \mathrm{c} 2 \mathrm{~h} 2 \mathrm{lb} / \mathrm{m}^{2}$

Pada gambar diatas menunjukan hasil uji metalografi pada tekanan $\mathrm{O} 22 \mathrm{lb}, \mathrm{c} 2 \mathrm{~h} 2$ $6 \mathrm{lb} / \mathrm{m}^{2}$. gambar di atas terlihat hampir tidak adanya lubang-lubang atau rongga-rongga pada material,hal ini di sebabkan karena hasil pemanasan yang baik,dan pada saat pendinginan tidak terlalu lama. Sehingga antara material saling cepat menyatu dan gasgas tidak dapat menggumpal di antara material.

\section{KESIMPULAN}

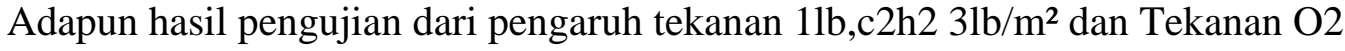
$2 \mathrm{lb}, \mathrm{c} 2 \mathrm{~h} 2 \mathrm{6lb} / \mathrm{m}^{2}$ adalah sebagai berikut.

1.Dari hasil pengujian tarik pada tekanan $\mathrm{O} 22 \mathrm{lb}, \mathrm{c} 2 \mathrm{~h} 2 \mathrm{6lb} / \mathrm{m}^{2}$ memiliki nilai rata-rata tegangan yang lebih besar yaitu 11.2 MPa dibandingkan nilai rata-rata dari tegangan $1 \mathrm{lb}, \mathrm{c} 2 \mathrm{~h} 2 \mathrm{lb} / \mathrm{m}^{2}$ yaitu sebesar $8.56 \mathrm{MPa}$. 
2.Dari hasil pengujian impact Pada tekanan gas $1 \mathrm{lb}, \mathrm{c} 2 \mathrm{~h} 23 \mathrm{lb} / \mathrm{m}^{2}$ nilai rata-rata dari energi yang diserap adalah $23.85 \mathrm{~mm}^{2}$ dan pada tekanan gas $21 \mathrm{~b}, \mathrm{c} 2 \mathrm{~h} 26 \mathrm{lb} / \mathrm{m}^{2}$ nlai ratarata dari energi yang diserap adalah $23.17 \mathrm{~mm}^{2}$.

3.Dari hasil pengujian kekerasan nilai tertinggi pada tekanan $\mathrm{O} 21 \mathrm{lb}, \mathrm{c} 2 \mathrm{~h} 2 \mathrm{3lb} / \mathrm{m}^{2}$ dengan nilai 100 dan nilai terendah terdapat pada tekanan O2 $2 \mathrm{lb}, \mathrm{c} 2 \mathrm{~h} 2 \mathrm{6lb} / \mathrm{m}^{2}$ dengan nilai 80 . Hal tersebut dikarenakan hasil tegangan sisa lasan yang lebih besar. Sehingga lasan pada specimen lebih baik. Adapun tegangan sisa mempengaruhi besarnya ketangguhan dari hasil lasan, karena tegangan sisa juga bertindak sebagai beban yang tetap yang akan menambah nilai beban kerja yang diberikan dari luar, sehingga ketangguhan las pada tekanan $\mathrm{O} 22 \mathrm{lb}, \mathrm{c} 2 \mathrm{~h} 2 \mathrm{6lb} / \mathrm{m}^{2}$ lebih baik.

4.Pada pengujian metalografi terdapat banyaknya lubang-lubang atau ruang-ruang kosong diantara material ( porositas ) pada tekanan $\mathrm{O} 2 \mathrm{llb}, \mathrm{c} 2 \mathrm{~h} 23 \mathrm{lb} / \mathrm{m}^{2}$ ini terjadi karena semakin lama waktu pada proses pengelasa,maka semakin lama proses pendinginan.hal tersebut akan menimbulkan gumpalan gas yang terperangkap.sedangkan pada tekanan $\mathrm{O} 22 \mathrm{lb}, \mathrm{c} 2 \mathrm{~h} 2 \mathrm{6lb} / \mathrm{m}^{2}$ hampir tidak adanya porositas, karena hasil pemanasan yang baik,dan pada saat pendinginan tidak terlalu lama. Sehingga antara material saling cepat menyatu dan gas-gas tidak dapat menggumpal di antara material.

\section{DAFTAR PUSTAKA}

1. http://www.mesinteknik.blogspot. com

2. S, Widharto, 2007. Menuju Juru Las Tingkat Dunia, cetakan pertama,Jakarta, Pradnya Pramita.

3. http://www.aluminiumlearning. com

4. W, Harsono. T, Okumura, 2000. Teknologi Pengelasan Logam. Pradnya Pramita,Jakarta Cetakan ke VIII.

5. www.umist.ac.uk/matsci 